EDWARD M. GRAMLICH

University of Michigan

\title{
An Econometric Examination of the New Federalism
}

President Reagan unveiled a set of proposals in February 1982 for fundamentally altering U.S. federal-state fiscal relations. He first proposed a massive program "swap" whereby the federal government would take over sole responsibility for the large and rapidly growing medicaid program and the states would assume sole responsibility for the main U.S. income support programs-food stamps and aid to families with dependent children (AFDC). He also proposed various ways to loosen strings heretofore accompanying categorical grants-many grants would be converted from categorical to block-grant form (continuing a trend begun a decade earlier in the Nixon administration), and many categorical and block grants would then be placed in a trust fund, the financial responsibility for which would eventually revert to state governments. Finally, he proposed rather sharp cutbacks in all forms of intergovernmental aid, cutbacks that would normally be front page news but in fact were upstaged by the more fundamental structural proposals.

In this paper I try to construct an analytical framework for evaluating

I owe a special debt of gratitude to Deborah S. Laren for working out some rather complex data processing schemes and to Judith Jackson for typing the paper on a stillevolving text-edit routine, both with a great deal of skill under the pressure of a time constraint. Patrick Driessen, Sharon Gennis, and Marieka Klawitter also provided able assistance gathering and processing data. Richard A. Kasten generously supplied some of the data. Many ideas surfaced when I presented an early version of this paper at the University of Michigan's public finance workshop, and many more when I circulated a draft to the editors and discussants of the Brookings Panel. Harvey Galper, Helen F. Ladd, Xavier Maret, and Daniel L. Rubinfeld also made helpful comments. 
these proposals. Their details have been debated extensively since February, and there seems little point in rehashing this debate. ${ }^{1}$ But the president's proposals do raise some deeper philosophical and empirical issues regarding the structure of both income-support programs and categorical grants, and these issues have until now received relatively little discussion. The paper is an attempt to fill that void.

I begin with an analysis of the most central, and interesting, issuewhether responsibility for income-maintenance programs should rest with the states as President Reagan has proposed; with the federal government as many, including previous presidents, the Advisory Commission on Intergovernmental Relations, and David Stockman have proposed; or whether income-maintenance should continue as a shared responsibility. ${ }^{2}$ This normative discussion highlights the critical role played by some key state behavioral response parameters and leads to the development of an empirical model aimed at estimating these parameters. The parameters also permit a simulation of the impacts of the president's "new federalism" proposals on levels of income maintenance throughout the country.

I then address the other side of the question, the impact of categorical grants, block grants, fund cutbacks, and the like on state budgets. I adopt a model used previously in $B P E A$, but tailor it to analyze the president's new proposals. ${ }^{3}$

1. The proposal is described in Office of Management and Budget, Major Themes and Additional Budget Details, Fiscal Year 1983 (Government Printing Office, 1982). An updated version is OMB, "Tentative Administration Decisions on Federalism Initiative" (June 22, 1982). A critical analysis can be found in Edward M. Gramlich and Deborah S. Laren, 'The New Federalism,'” in Joseph A. Pechman, ed., Setting National Priorities: The 1983 Budget (Brookings Institution, 1982), pp. 151-86.

2. Federalizing public assistance has been an important component of the welfare reform plans proposed by both Presidents Nixon and Carter. In June 1980 the Advisory Commission on Intergovernmental Relations singled out income maintenance and food stamps as programs that should be operated at the federal level. David A. Stockman's views on the matter were stated, somewhat vaguely, in "The Social Pork Barrel," Public Interest, vol. 39 (Spring 1975), pp. 3-30. One of the clearest statements in favor of nationalization of income maintenance by an economist can be found in Wallace E. Oates, Fiscal Federalism (Harcourt, Brace, Jovanovich, 1972), chap. 1. Oates has not changed his view since his book was written; see his "The New Federalism: An Economist's View" (University of Maryland, 1982). A theoretical paper that analyzes various subcases, sometimes arriving at different conclusions, is by Mark V. Pauly, "Income Redistribution as a Local Public Good," Journal of Public Economics, vol. 2 (February 1973), pp. 35-58.

3. The model follows, without too much change, that in Edward M. Gramlich and Harvey Galper, "State and Local Fiscal Behavior and Federal Grant Policy," BPEA, 


\section{The Federal Role in Income Maintenance}

In a democracy it is natural to assume that the level of income support should be determined by the voters. However, the question of whether income-support programs should be determined at the national or state level, or as a shared responsibility, has no easy answer. Since voters are at the same time citizens of the national and a state government, they or their representatives cannot simultaneously set one level of benefits that obtains throughout the nation and another level within a state. Two arguments are usually made for determining benefits at the national level. One is the claim, which can be posed in public choice terms, that voters feel a responsibility for supporting beneficiaries throughout the country at certain minimal living standards. It might be felt, for instance, that especially insofar as children and young families are concerned, a certain level of income support is a basic national right of beneficiaries. ${ }^{4}$ If particular states choose not to provide such minimum support, there is a psychic externality to voters in other states, hence national actions to constrain state choices are justified.

A second argument for granting the national government priority in the setting of AFDC benefits rests on the possibility for migration. If state legislators perceive that AFDC beneficiaries will immigrate to states with relatively high benefits, and taxpayers will emigrate from states with relatively high taxes, they will keep benefits below the level that would otherwise maximize the collective welfare of a state's existing residents. This tendency exists even if all states have identical preferences about income support. ${ }^{5}$ The immigration flows cannot be limited

1:1973, pp. 15-58; it was later simplified and modified in Gramlich, "State and Local Budgets the Day After It Rained: Why Is the Surplus So High?" BPEA, 1:1978, pp. 191214.

4. The first claim is proposed most clearly in Helen F. Ladd and Fred C. Doolittle, "Which Level of Government Should Assist the Poor?" National Tax Journal, vol. 35 (September 1982), pp. 323-36. They also cite a poll by the Advisory Commission on Intergovernmental Relations suggesting that most respondents view income support as a national responsibility. The latter claim is argued in Arthur M. Okun, Equality and Efficiency: The Big Tradeoff (Brookings Institution, 1975), chaps. 1 and 4.

5. In fact, as Pauly points out, the normative implications of migration can be quite complicated. When the migration is that of positive taxpayers, it is difficult to tell a priori whether redistribution policy should be made at the national or state (or local) level. But when the migration is that of potential beneficiaries, Pauly's model implies that the standard 
by residency requirements, which are now considered unconstitutional by the Supreme Court. ${ }^{6}$

Is it possible to structure a scheme that satisfies this second argument, provides at least some minimum support defined by national preferences, and also allows scope for differences in preferences among states? At least three ways for structuring state and national responsibilities have been put forth. One, advanced by Tresch, is a hierarchical redistribution system. ${ }^{7}$ Under this plan, the national government would redistribute income among states, the states among localities, and the localities among households. Legislators could vote for as much or as little redistribution as they wanted at each level of government. Migration or the anticipation of it would not distort the pattern of benefits in such a system because a generous locality would be entitled to greater transfers from higher levels of government if low-income families moved into it and high-income taxpayers moved out. If migration were costless, impoverished individuals in localities providing inadequate benefits could move and their doing so would not add to the burden of the locality to which they moved. But if migration were costly, such a system would work little better than a decentralized system in which only states set benefit levels: there would be no way for legislators representing national preferences to ensure that low-income people were taken care of in particular states. Moreover, even if migration were not costly and the system worked as it should, the outcome might not be socially desirable because the scheme could in the long run lead to extreme differences in state and local incomes.

A second possible approach follows similar proposals in education. States could decide on benefit levels, but in the presence of federal "power equalization"' grants that neutralize the impact of state income in determining these benefit levels. Hence public assistance beneficiaries in low-income states would, apart from preference (nonincome) differ-

argument given here is usually correct: redistribution should be done at the national level, or national tastes should take priority. See Pauly, "Income Redistribution."

6. In 1969, the Court held that residency requirements are unconstitutional restrictions on free interstate travel and that such laws constitute "invidious discrimination" in distinguishing between poor persons who are long-term residents of a state and those who are not. This decision could be reexamined at any point: some states have recently tried to adopt residency requirements that are yet to be challenged.

7. See Richard W. Tresch, Public Finance: A Normative Theory (Business Publications, Inc., 1981), chap. 30. 
ences, be supported at the same expected level as those in high-income states. Such a scheme would consist of a matching grant AFDC program, with matching rates inversely correlated with state income. Feldstein has shown how state matching rates can be computed so as to make expected AFDC benefit levels independent of state income. ${ }^{8}$ Assume that AFDC benefits are determined by a log-linear demand function of the form

$$
B=c_{0} e^{c_{1} Z} \hat{Y}^{c_{2}} \boldsymbol{P}_{B^{3}}^{-c_{3}},
$$

where $B$ is the AFDC benefit level in a state; $\hat{Y}$, average state per capita income; $P_{B}$, the effective price of benefits to the state per dollar (or, equivalently, the state's share); and $Z$, some preference variable assumed to be uncorrelated with income. If the relevant elasticities are constant among states in the way specified, and the federal grant is open-ended, authorities can offset income differences by making the federal share, $m$, itself depend on income. In particular, if

$$
P_{B}=(1-m)=c_{4} \hat{Y}^{c_{5}},
$$

then

$$
\frac{\partial \ln B}{\partial \ln \hat{Y}}=c_{2}-c_{3} c_{5} .
$$

Thus if the federal authorities set $c_{5}=c_{2} / c_{3}$, expected state benefit levels are made independent of state income. The level of $c_{4}$ determines the average level of benefits. The higher is the income elasticity, $c_{2}$, the more $B$ is likely to be high in high-income states, and the more this tendency would need to be offset by a generous matching formula for low-income states. Conversely, the greater in absolute value is the price elasticity, $c_{3}$, the less reason there is for a generous matching rate.

But even though an open-ended grant of this sort will reduce or eliminate the income-generated disparity in income-support levels, it will not eliminate the disparity caused by other preference differences among states. The preference for redistribution may vary widely across states, and, if it does, benefit levels will also vary widely, even with power equalization. Voters might want a higher level of income support in a particular state and be unable to bring it about.

8. Martin S. Feldstein, "Wealth Neutrality and Local Choice in Public Education," American Economic Review, vol. 65 (March 1975), pp. 75-89. 
A different grant policy variant could potentially have a stronger effect in reducing the statewide variation in benefits. If matching rates depended not on the independent variable, $Y$, but on the dependent variable, $B$, the budget line facing states would not be linear but convex (or piecewise linear). The federal government could match a high share of the first $X_{1}$ dollars in AFDC benefits, a lower share of the next $X_{2}$ dollars, and so forth. The price incentives in such a scheme could be chosen so as to make states cluster around the desired level of benefits, hence reducing the statewide variance in benefits. If the matching rates were in addition made to depend on state income, the virtues of both approaches could be combined.

A third broad approach is the more straightforward one of state supplementation. Under this approach the national government would set a basic guarantee level for the nation. States could then choose to supplement this guarantee or not. To preserve the national priority, it must not be possible for the states to "tax away" the national benefits by reducing their own benefits. But while this scheme does establish the basic guarantee level consistent with national preferences, it does not necessarily result in state supplemental benefits that reflect the desires of voters in states choosing to supplement the national floor. State supplementation levels could still be kept down by fear of migration.

It is also possible to combine the second and third approaches-state supplementation with power equalization. Under this scheme there would be a basic national benefit level that could not be taxed away by states. States would be empowered to supplement this national benefit level to the extent desired. Matching federal grants would make expected state supplementation levels independent of state income by power equalization. The national floor avoids the main criticism of a pure power-equalization scheme with an open-ended grant. The powerequalization grant eliminates income as a source of disparity in supplemental benefits and would reduce the importance of migration fears. And convexities in the grant schedule could reduce disparities even more.

The present system can be likened to this hybrid scheme and has many of its virtues. The basic national benefit level can be thought of as food stamps, a national program available to most low-income families with a basic level of support ( $\$ 233$ a month for a family of four in 1981). In addition to this, all states supplement food stamps with AFDC 
payments, which are available to low-income families with female heads of household and (in twenty-six states) families with unemployed male heads. ${ }^{9}$ For most of these ranges AFDC payments are financed by an open-ended federal matching grant with state shares $(1-m)$ varying between 22 and 50 percent, depending on state income. For very low benefit levels, there is even a convex grant schedule, with the state share being just 17 percent for the first $\$ 72$ per month for a family of four and a higher amount that depends on state income for the next $\$ 56$ per month. ${ }^{10}$

But although in its general structure the current system can accommodate national and state preferences without the major disadvantages of many other schemes, how it actually works depends on some key behavioral parameters. One factor is that states may appear to supplement food stamps, but in fact respond to food stamp guarantee increases by reducing their AFDC benefits dollar for dollar. If so, the national benefit floor is less effective at the margin than it seems: within some range, it may prove impossible for national legislators to alter nationwide minimum benefits by changing food stamp guarantee levels. Another factor is that the matching grant structure may be less than ideal. The state matching shares may not be well correlated with the Feldstein neutral values given by equation 3 above. If so, expected supplementation levels are not independent of state income. And even if they are, the impact of preferences or other independent variables could still cause such a wide variation in actual supplementation levels that the national priority in setting income-support benefits could not be effec-

9. A similar program structure is in place for the aged, blind, and disabled. The basic national floor is called Supplemental Security Income, which now pays $\$ 426$ a month for a couple with no other income. All states except Texas also provide supplementary benefits, though without the advantage of federal matching shares.

10. This convex schedule was a feature of the original AFDC law, passed as part of the Social Security Act of 1935 . Although the convex schedule could greatly reduce the statewide variation in benefits, it has been allowed to wither away by the combined effect of inflation (the kink points have not been indexed and thus have declined enormously in real terms over the years) and the introduction of medicaid in 1965. The medicaid law gave states the option of being reimbursed by their medicaid formula, an open-ended federal grant with state shares depending on income and varying between 22 and 50 percent, as stated in the text. By now, all but two states have switched to the medicaid formula: Arizona, which does not have medicaid (though it soon will), and Texas, where AFDC benefits are actually limited in the state constitution to a level at which the old convex schedule dominates. 
tively established without a convex grant schedule. A third factor is that the optimality of any set of state supplementation benefits depends on the strength of migration perceptions. If migration of potential beneficiaries is perceived to be highly sensitive to rises in benefit levels, or if states are influenced by benefits in neighboring states for any other reason, these states are thrown off their "closed economy" preferred support levels, and the appearance that state supplementation levels satisfy state choices is again hollow. The remedy for each of these problems would be a more centralized system, with higher national benefit levels and less reliance on state supplementation-exactly the reverse of what the president is now proposing.

\section{A Model of the Determination of AFDC Benefit Levels}

The foregoing discussion shows that empirical estimates of critical behavioral response parameters are necessary to evaluate the present income-support system and any proposals for reforming it. There have been previous attempts at explaining AFDC benefit levels, but none focuses on all these key behavioral parameters. In this section, I develop a model of state determination of AFDC benefits that has such a focus.

A first question in building any model of the determination of AFDCsupport levels is why public assistance benefits are paid at all. Essentially four political-economic models have been proposed in the literature: (1) the altruism model of Orr, Pauly, and others, ${ }^{11}$ in which voters support welfare benefits because they want to raise living standards of the poor, balancing the marginal gain in terms of the utility from higher benefits with the marginal cost in terms of private goods that are sacrificed; (2) the vote-buying model of Peltzman and others, ${ }^{12}$ whereby politicians raise AFDC benefits because they are buying votes from their low-

11. Larry L. Orr, "Income Transfers as a Public Good: An Application to AFDC," American Economic Review, vol. 66 (June 1976), pp. 359-71; and Pauly, "Income Redistribution." The spirit of Orr's model follows that of income-transfer models developed earlier by many authors (cited in his paper), but Orr has developed the empirical model that best fits prevailing U.S. federalism conventions.

12. Sam Peltzman, "The Growth of Government," Journal of Law and Economics, vol. 23 (October 1980), pp. 209-87. A model in the same tradition is Allan H. Meltzer and Scott O. Richard, "Why Government Grows (and Grows) in a Democracy," The Public Interest, vol. 52 (Summer 1978), pp. 111-18. 
income constituents, expanding the program until the marginal political gain among potential beneficiaries equals the marginal political loss among potential taxpayers; (3) the income-security model of Varian, ${ }^{13}$ in which voters favor income-support programs not to help others, but to limit the variation in their own income in a world of uncertainty about their income; and (4) the regulation model of Piven and Cloward, ${ }^{14}$ in which AFDC is used as a device to maintain civil order by controlling the poor, adding them to the welfare rolls in periods when disorder threatens and removing them from the rolls when its threat subsides.

These models are not mutually exclusive, and there is no reason why AFDC benefits cannot be paid to satisfy a variety of objectives. In many cases the empirical formulation of each model will look quite similar, so that it is difficult for real world tests to discriminate among the models.

But there are a few cases in which the models would imply quite different behavior. One has to do with income in the state. Under the altruism model, as taxpayers become more affluent, they should want to consume more of a range of public and private goods, including incomesupport levels. Under the vote-buying model, the sign of income may well be reversed, as a rise in income could indicate fewer votes to be bought by pandering to those with lower incomes. Under the security model, the same could be true, as fewer voters may fear that drops in income would bring them under AFDC standards. Similarly, according to the regulation model, higher incomes imply fewer poor people and therefore fewer people needing control.

A similar difference could exist with migration incentives. In the altruism model, for a given level of benefits in surrounding states, the higher the cost of raising benefits is, the lower are predicted benefit levels in a particular state. But under the vote-buying model, a rise in benefits could be an attempt to buy voters from outside the state by attracting migrating AFDC beneficiaries, hence raising the net gain to politicians and raising benefit levels. So it goes.

13. Hal R. Varian, "Redistributive Taxation as Social Insurance," Journal of Public Economics, vol. 14 (August 1980), pp. 49-68.

14. Frances Fox Piven and Richard A. Cloward, Regulating the Poor: The Functions of Public Welfare (Pantheon Books, 1971). They too have not changed their view, and indeed have a recent book explaining Reagan's attempted cuts in social programs (of which the new federalism is one aspect) by the fact that the explicit threat of civil disorder is subsiding now. See Piven and Cloward, The New Class War: Reagan's Attack on the Welfare State and Its Consequences (Pantheon Books, 1982). 
Without taking sides on the validity of these models, in this paper I take a general utility-maximization approach that could be consistent with some composite of all theories. The model is similar in spirit to that developed by Orr, but different because it highlights the parameters most relevant to understanding the effects of distributing more responsibility to the states-the parameters describing how state AFDC benefits respond to national food stamp levels (and, in principle, to medicaid support) and to benefits in other states as a result of migration perceptions.

Assume that state legislators are motivated by the utility function,

$$
U_{i}=U_{i}\left(X_{i}, B+a F\right),
$$

where $U_{i}$ refers to the quasi-concave utility function of the decisive $i$ th voter in a state, the voter who, through a set of complex political mechanisms, will determine state policy; $X_{i}$ is the disposable income of the voter; $B$ is the average income-support benefit level in the state; and $F$ is the benefit level in the food stamp program. ${ }^{15}$

I assume that food stamp benefits are determined exogenously by the federal government and that a utility weight, $a$, is applied to those benefits; I assume that the state legislators maximize utility by manipulating $B$, balancing gains and costs at the margin. A wide range of values for $a$ is possible. If food stamps are perceived by the decisive voter as fully substitutable for money, $a$ should be 1.0. If food stamps are considered in-kind benefits and are viewed as less desirable than cash support, $a$ should be less than 1.0. If the decisive voter prefers to give in-kind assistance rather than cash assistance, $a$ could even be greater than 1.0. And, if the decisive voter takes no account of the other programs in deciding on support levels for AFDC, $a$ should be zero.

The two identities that give the budget constraint in this system are, for the household,

$$
X_{i}=Y_{i}(1-t),
$$

15. Medicaid benefits can, in principle, be treated symmetrically with food stamp payments in this model, and the reader can consider both in this conceptual discussion. But as I explain below in discussing the empirical implementation of the model, it proved impossible to obtain the data needed to introduce medicaid payments, so I omit them from the analysis. 
where $Y_{i}$ is personal income before taxes and $t$ is a proportional tax rate used to pay for AFDC benefits; ${ }^{16}$ for states,

$$
t \hat{Y}=(1-m+m z)(R B / N),
$$

where

$$
\begin{aligned}
\hat{Y} & =\text { average per capita income in the state } \\
N & =\text { state population } \\
m & =\text { federal matching rate as before, with the grant as- } \\
& \text { sumed to be open-ended } \\
R= & \text { number of AFDC recipients } \\
z & =\text { ratio of state to federal income and } \\
1-m+m z & =\text { total cost to state taxpayers of raising AFDC benefits. }
\end{aligned}
$$

Taxpayers pay $(1-m)$ directly, and then must pay $100 z$ percent of all federal matching expenses. Since the tax rate $t$ finances both the state share and part of the federal share, it includes both state and federal taxes: Note also that only $B$ appears in the budget identity: $F$ is paid for by the federal government and need not be financed by taxpayers in a state.

To this point the maximization exercise is a standard one of maximizing utility subject to these two budget constraints. The complicating feature in the AFDC system is that the recipient population cannot be viewed as exogenous, but instead depends on benefit levels in surrounding states. Defining these benefit levels as $\bar{B}$, an equation that expresses how legislators perceive the relation between the number of recipients and relative benefit levels is

$$
R=\hat{R}(B / \bar{B})^{b},
$$

where $\hat{R}$ is the number of recipients in a state in which benefits received in that state are equal to benefits available outside the state, and $b$ is the perceived migration elasticity. ${ }^{17}$

16. At this point one might ask whether the federal tax deduction for state taxes should be included in equation 5 . Since $(1-t)$ solves out of the theoretical model in the way I use it, this question is not of great practical importance. But even apart from this, because most voters do not itemize deductions, the decisive voter may not. I took the liberty of ignoring the federal deduction.

17. Although the conventional wisdom among students of AFDC is that it is hard to 
The model is solved by assuming some functional form for the utility function and substituting in the constraint equations 5,6 , and 7 to determine the tax price of benefits. Because the system contains both nonlinear and linear equations, some approximations are necessary to arrive at an estimating equation.

A first way to solve the model is to approximate the benefit equation implied by the utility function by

$$
B=c_{0} e^{c_{1}{ }^{Z}} \hat{Y}^{c_{2}} \boldsymbol{P}_{B^{3}}^{-c_{3}} F^{-c_{6}},
$$

where the elasticity $c_{6}$ is assumed to be

$$
-c_{6} \equiv \partial \ln B / \partial \ln F=(\partial B / \partial F)(\hat{F} / \hat{B})=-a(\hat{F} / \hat{B}),
$$

where $\hat{F}$ refers to average food stamp levels in a state and $\hat{B}$ to average AFDC benefits, with each average taken over time for the state. Expressing this elasticity in this form makes it an explicit function of the coefficient $a$, which can then be estimated directly by substituting into 8 to obtain

$$
\ln B=\ln c_{0}+c_{1} Z+c_{2} \ln \hat{Y}-c_{3} \ln P_{B}-a(\hat{F} / \hat{B}) \ln F .
$$

Using 5,6, and 7 yields

$$
X_{i}=Y_{i}-\left(Y_{i} / \hat{Y}\right)(1-m+m z)(\hat{R} / N) B^{b+1}(\bar{B})^{-b},
$$

so that

verify equations like 7 with direct evidence, in fact there is at least one study that appears to do that. Using a large-scale survey of AFDC recipients taken in 1967, Lawrence Southwick, Jr., has estimated large and statistically significant $b$ values in specifications similar to 7. Southwick's data apparently only contain information on the birthplace and the place of receipt of benefits for AFDC recipients, by the nine census regions in the United States, and the results of his study should be accepted with a good deal of caution. But the apparent impact of AFDC benefits on migration is quite strong. See his "Public Welfare Programs and Recipient Migration," Growth and Change, vol. 12 (October 1981), pp. 22-32.

Moreover, even if recipients themselves were not strongly influenced by relative AFDC benefit levels, if for any reason legislators took their cue from other states in the setting of benefits, the model developed below would work as formulated. The political science literature contains one such rationale-political diffusion of innovations in state policy. Under this theory, policy changes spread like "ink blots" across the national map. See, for example, Jack L. Walker, "The Diffusion of Innovations among the American States," American Political Science Review, vol. 63 (September 1969), pp. 880-99; and Ira Sharkansky, "Regionalism, Economic Status, and the Public Policies of American States," The Social Science Quarterly, vol. 49 (June 1968), pp. 9-26. 


$$
P_{B}=-\left(\partial X_{i} / \partial B\right)=(b+1)\left(Y_{i} / \hat{Y}\right)(1-m+m z)(\hat{R} / N) B^{b}(\bar{B})^{-b},
$$

and, inserting into 10 to give an estimating equation yields ${ }^{18}$

$$
\begin{aligned}
\ln B= & {\left[1 /\left(1+c_{3} b\right)\right]\left\{\ln c^{\prime}+c_{1} Z+c_{2} \ln \hat{Y}\right.} \\
& -c_{3}[\ln (1-m+m z)+\ln (\hat{R} / N)] \\
& \left.+c_{3} b \ln \bar{B}-a(\hat{F} / \hat{B}) \ln F\right\},
\end{aligned}
$$

where $c^{\prime}$ is a new intercept term that includes all of the constants in 12 . The econometric problem in estimating 13 when $B$ and $\hat{B}$ are correlated in cross-sections is dealt with by including state dummy variables as explained below. The inclusion of state dummies along with $\bar{B}$ leaves relatively little opportunity for variations in $F$, either across states or through time, to explain $B$. Thus one would not expect to estimate $a$ with much precision using equation 13 .

An alternative way to estimate the model is to take a different logarithmic approximation of the basic benefits equation:

$$
B+a F=c_{0} e^{c_{1} Z} \hat{Y}^{c_{2}} P_{-{ }_{B}}^{c_{3}} .
$$

In this version the migration relation in 7 was replaced by

$$
R=\hat{R}(B+a F)^{b}(\bar{B}+a \bar{F})^{-b},
$$

where $\bar{B}$ and $\bar{F}$ refer to benefit levels in surrounding states. This formulation required an additional simplifying assumption to get to the estimating equation: ${ }^{19}$

$$
\begin{aligned}
\ln (B+a F)= & {\left[1 /\left(1+c_{3} b\right)\right]\left\{\ln c^{\prime}+c_{1} Z+c_{2} \ln \hat{Y}\right.} \\
& -c_{3}[\ln (1-m+m z)+\ln (\hat{R} / N)] \\
& \left.+c_{3} b \ln (\bar{B}+a \bar{F})\right\}
\end{aligned}
$$

19. The approximation involves assuming the expression $[1+b B /(B+a F)]$, which comes from differentiating 11 with 15 substituted in, is constant. It can be seen that when $a=0$, the expression truly is constant. When $a>0$, the term in brackets involves the ratio of AFDC benefits $(B)$ to what might be called full benefits $(B+a F)$ in the particular state. There is no obvious way to solve this expression so that it is included in the dependent variable; nor is there an easy way to deal with it in estimation without introducing simultaneous equations bias once again. So I just made the simplifying assumption and compared results of estimating the model this way with the results of estimating it from 13. 
This expression can only be estimated by assuming different values for $a$ and searching for the value that maximizes the fit. Because the effect on the estimates of the simplifying assumption needed to derive 16 is unclear, I discuss the model mainly using 13 . However, I also refer to the results of estimating 16 in considering the uncertainty with which some important parameters are estimated.

\section{EMPIRICAL IMPLEMENTATION}

Estimating the benefits equations presented complex data problems and required several compromises and approximations to be made. These need to be addressed before turning to the empirical results and their interpretation. The model was fitted to pooled time-series, crosssectional data on state AFDC payments for 1974-81. Although as a general rule added data points are valuable, there are several reasons for not beginning the sample before 1974. One is that casual evidence on the growth of AFDC benefit levels suggests that views about welfare may have changed since the late 1960s and early 1970s: in most states, average real benefit levels were generally rising until the early 1970 s and have been generally declining since. Moreover, food stamps were not available in all counties until 1974, and it is quite difficult to measure the value of $F$ for individual states before 1974. Finally, as explained below, it is more difficult to deal with matching rates before 1974 .

Measuring AFDC Benefits. Each of the AFDC variables requires some explanation. The dependent variable in $13, B$, measures the generosity of a state's AFDC plan. It can be expressed as

$$
B=G-s_{1} E-s_{2} U,
$$

where $G$ is the guarantee level, or payment to a family with zero outside income; $E$ is earned income; $U$ is unearned income; and $s_{1}$ and $s_{2}$ are benefit reduction, or implicit tax, rates. All variables vary widely across states, and this makes it difficult to characterize state plans in one dimension.

The least satisfactory approach, though that followed in most other empirical studies of AFDC, is simply to use average statewide benefits per recipient as a measure of $B$. One disadvantage of this approach is that guarantee levels depend on family size, so observed benefit levels will vary among states and over time if family sizes vary. Another 
disadvantage is that earned income clearly depends on both guarantee levels and tax rates. As $G$ increases in a state, $E$ will decrease, and observed benefit levels will decrease by varying amounts because the implicit tax rate, $s_{1}$, varies. This tax rate was supposedly fixed at 67 percent by the 1967 amendments to the Social Security Act, but because states allow differing amounts of work-related deductions, effective tax rates on earnings have been estimated to range from 2 percent in Missouri to 43 percent in Connecticut. ${ }^{20}$ Hence observed benefit levels should be correlated rather poorly with some true index of state AFDC policy.

Measuring $G$ by the statewide guarantee level for a family of standard size avoids both of these difficulties. Such a measure obviously is affected neither by variation in actual family size nor by endogenous responses of $E$ to this guarantee. But while $G$ is fully exogenous, it may not be fully informative. On the one hand, states exercise a good deal of administrative discretion over both payment levels and eligibility, discretion that may not be captured in or correlated with $G$. On the other hand, statewide variation in the implicit tax rates on benefits, $s_{1}$ and $s_{2}$, is also relevant, and is not reflected in the $G$ variable.

A sensible solution to this problem, one familiar to budget analysts who compute a full-employment surplus, is to subtract from standardized guarantee levels standardized values of $s_{1} E$ and $s_{2} U$ or

$$
B=G-s_{1} \bar{E}-s_{2} \bar{U},
$$

where the $s_{1}$ and $s_{2}$ are estimated for a state and the $\bar{E}$ and $\bar{U}$ values are standardized for all states. This is what $I$ have done in the empirical work described below. $G$ levels are taken as guarantee levels for an AFDC family of four (mother and three children), expressed in 1981 dollars. The $\bar{E}$ and $\bar{U}$ are taken from 1976 values in Michigan's Panel Study of Income Dynamics, as reported by Moffitt, again converted to 1981 dollars for an AFDC family of four. ${ }^{21}$ The tax rates were taken from Moffitt's estimates of effective tax rates for various states from a large-

20. The two articles that first laid out these problems are Irene Lurie, "Estimates of Tax Rates in the AFDC Program," National Tax Journal, vol. 27 (March 1974), pp. 93111; and Robert M. Hutchens, "Changes in AFDC Tax Rates, 1967-1971," Journal of Human Resources, vol. 13 (Winter 1978), pp. 60-74. My numbers are taken from a recent estimation of the parameters of state plans by Robert A. Moffitt, "An Economic Model of Welfare Stigma"' (University of Wisconsin, October 1981).

21. Moffitt, "An Economic Model." 
scale 1975 AFDC survey. This survey was only done for one year, so my $B$ series contains no time-series variation in tax rates for particular states (though it does for the guarantee level). Also, because of small cell sizes, Moffitt reports tax rates for only thirty-five states.

Food Stamps. To be consistent with the treatment of AFDC benefits, the food stamp benefits term, $F$, was measured for an AFDC family of four in 1981 dollars with average values according to the Michigan study for $E$ and $U$. Although $I$ have treated $F$ as exogenous in deriving the theoretical model, in fact it is not fully exogenous from an econometric standpoint because the food stamp program contains an implicit tax on AFDC benefits: as a state raises $B$ one dollar, its $F$ value declines by a statutory amount of $\$ 0.30$ and an actual amount of somewhat less. This raises the possibility of simultaneous equations bias in estimating the model. I dealt with this problem by using a two-stage least squares procedure in which actual $F$ values were everywhere replaced by their first-stage predictions (based on a regression of $F$ on the system's exogenous variables) in estimating the benefits equations.

The Federal Matching Rate. The next variable requiring explanation is the AFDC matching rate, $m$. As stated above, from its early days AFDC has operated with a matching grant formula under which the federal government pays a progressively declining share of AFDC benefits as $B$ levels rise. Estimating the relevant response parameters in such a circumstance raises substantial econometric difficulties. It is possible to deal with such problems, ${ }^{22}$ but the attempt would be mainly of historical or methodological interest. By 1974, forty-one (twentyseven in my sample) states had switched over to the flat, open-ended medicaid formula for AFDC reimbursement, and by 1979 all states except Arizona and Texas (making thirty-three in my sample) had switched. To spare the econometric problems, I just fit the model for the thirty-three states that were on the medicaid formula. ${ }^{23}$

$\bar{B}$ in Surrounding States. In terms of the theory as expressed in equation $7, \bar{B}$ for a particular state should refer to AFDC guarantee levels

22. See, for example, Robert A. Moffitt, "The Effects of Grants-in-Aid on State and Local Expenditures: The Case of AFDC," to be presented at a National Bureau of Economic Research conference, November 1982, for one such attempt.

23. This meant that the sample size was twenty-seven states in my sample on the medicaid formula for the duration multiplied by seven annual observations (1975-81) plus six midterm switchers multiplied by three annual observations (1979-81), for a total of 207 pooled observations. 
either in those states from which recipients would be most likely to emigrate or in states that, for one reason or another, are considered worth emulating (see note 17). Very little is known about how AFDC beneficiaries or positive taxpayers are perceived to respond to fiscal inducements, or about emulation in general. One way to deal with this is to define $\bar{B}$ as average benefit levels in states bordering on the particular state. This approach gives the strict construction of what is meant by a surrounding state, and reflects the fact that moving costs should depend on the distance moved. Another is to assume that moving involves high fixed costs and low marginal costs, and then simply take AFDC benefits averaged in all other states as the measure. This latter approach works better in the empirical work and is the definition used in the results presented below. Since the response to benefit differences is likely to be lagged, $\bar{B}$ is defined to be a weighted average of the current and recent past values with declining weights.

Medicaid Payments. As I observed in note 15, in principle medicaid payments should be treated in parallel with food stamp benefits. From a policy standpoint, there would also be interest in including medicaid in this model because medicaid payments are also slated to change in the new federalism proposals. However, there are severe data problems in trying to model medicaid.

Nationally medicaid appears to dominate both AFDC and food stamps; in fiscal 1981 federal and state medicaid expenditures were \$29 billion, food stamp expenditures were $\$ 11.3$ billion, and AFDC expenditures were $\$ 14.7$ billion. But medicaid plays a much smaller role in an AFDC model than one might expect on the basis of these numbers because, of the $\$ 29$ billion in medicaid expenditures, only about onefourth is devoted to the AFDC population. The remainder finances gaps left by medicare-nursing home expenses and coinsurance, deductibles, and premiums under medicare..$^{24}$ When medicare-type expenditures are deducted, medicaid becomes a much less significant factor. Another reason for de-emphasizing medicaid is that statewide data on medicaid expenditures per AFDC family are available only sporadically, for four of the seven years in the sample. Those data that are available show quite wide, and not very logical, fluctuations, from month to month and from year to year. If medicaid were to be included at all, it would only

24. See Louise B. Russell's section entitled "Health," in Joseph A. Pechman, ed., Setting National Priorities: The 1982 Budget (Brookings Institution, 1981), pp. 67-72. 
be as a variable that is constant for a particular state; it would become perfectly collinear with a state dummy; and because state dummies are necessary to estimate the model with $\hat{B}$ on the right-hand side, medicaid had to be dropped as an independent variable.

Price Correction. The effect of prices was modeled after some experimentation. All money-flow variables in the model are converted to 1981 dollars using the appropriate general price deflator (the overall consumer price index for $B$, the food index for $F$, and so on). This deflation puts everything in real terms but raises the possibility that nonindexed AFDC benefits will be temporarily lowered by unanticipated rises in prices. To test for this influence, I tried including the two-year change in prices, with an expected negative sign, to allow for price recognition and adjustment lags. I also tried to eliminate cross-sectional variation in prices by using the twenty-five-city CPI index, again with an expected negative sign, to reflect regional price differences. ${ }^{25}$

The other variables in the basic models (equation 13 or 16) are the base recipient-population ratio $(\hat{R} / N)$ and the preference vector, $Z$. To eliminate simultaneous variation in the former, it would be necessary to use some state average, again making this variable collinear with state dummies and forcing it to be dropped. For $Z$, as mentioned above, it was necessary to use separate dummies for each state to correct for the simultaneous equations bias that would otherwise result from having $B$ and $\hat{B}$ on opposite sides of the estimating equation 13 . I also included the ratio of recipients that were nonwhite and the state unemployment rate as additional shift variables.

To recapitulate, then, the basic models to be estimated are 13 and 16 . In each case an extensive set of preference variables (state dummies, and so forth) is used for the $Z$ vector; the $F$ variable is the result of a twostage least squares estimation; the $\hat{R}$ variable is a cross-sectional constant; and the $B$ terms are constructed in the complex way described above. Other than these exceptions, the models estimated are exactly as written.

25. That the cross-sectional sign should be negative can be seen as follows. Suppose 13 is expressed in terms of $B^{\prime}$ and $Y^{\prime}$, where $B^{\prime}=B(\bar{P} / \hat{P}), \bar{P}$ is the national price level, and $\hat{P}$ is some true regional price. Substituting $B^{\prime}$ and $Y^{\prime}$ into 13 yields the equation given there with one more term, $-\left[\left(1+c_{3} b-c_{2}\right) /\left(1+c_{3} b\right)\right] \ln (\bar{P} / \hat{P})$. Unless the income elasticity, $c_{2}$, is greater than 1.0 (which it does not seem to be in the estimates given below), this coefficient should be negative. 
ESTIMATES OF THE MODEL

Three estimates of the AFDC model are shown in table 1. The first row, equation 1-1, corresponds to equation 13; the second and third rows, $1-2$ and $1-3$, to 16 . Although $1-1$ and $1-2$ produce nearly identical estimates of the important coefficients and hence of the underlying parameters of the model that are of special interest for evaluating policy changes, I regard the results in 1-1 as the most reliable results available from these data because the derivation of equation 16 that underlies 1-2 and 1-3 is exact for the case when $a$ equals 0 as in 1-2, but involves a simplification otherwise. Nonetheless, the sharply different coefficients in 1-3 suggest the estimates are uncertain and must be viewed with caution.

Substitution between $B$ and $F$. The evidence from 1-1 that $a$ equals zero indicates that voters do not alter AFDC benefits in response to changes in federally funded programs such as food stamps. Thus it is possible for voters nationally to set a floor on total benefits, $B+F$, by setting a floor on $F$, and to change this floor by changing $F$. (The latter would not be true if $a$ were 1.0.) The present AFDC-food stamp system thus appears to allow for dual determination of floors for state and national benefits.

This $a$ parameter is important in assessing the impact of President Reagan's new federalism plan. Initially the president proposed turning food stamps back to the states along with AFDC. The revised proposal indicates that the administration has agreed to maintain food stamps as a national program, presumably because of strong objections by state governors. If $a$ equals zero, as the estimates here suggest, direct cash and in-kind benefits to the poor would have dropped sharply with the original federalism plan (by over 30 percent for the average state), and they will now not change in the revised plan. The poor have a great stake in the debate now taking place about which level of government is responsible for food stamps. ${ }^{26}$

Income and Price Elasticities. The next key parameters are the income and price elasticities, $c_{2}$ and $c_{3}$. For 1-1 and 1-2 in table 1 below, $c_{2}$ is roughly equal to $c_{3}$; for $1-3, c_{2}$ is twice as large as $c_{3}$. Equation 3

26. This comment ignores the income effect; if $F$ declines, the revenue will be returned to states and result in a very small (1 percent) change in their real income. That will raise AFDC benefits slightly through the income term. 


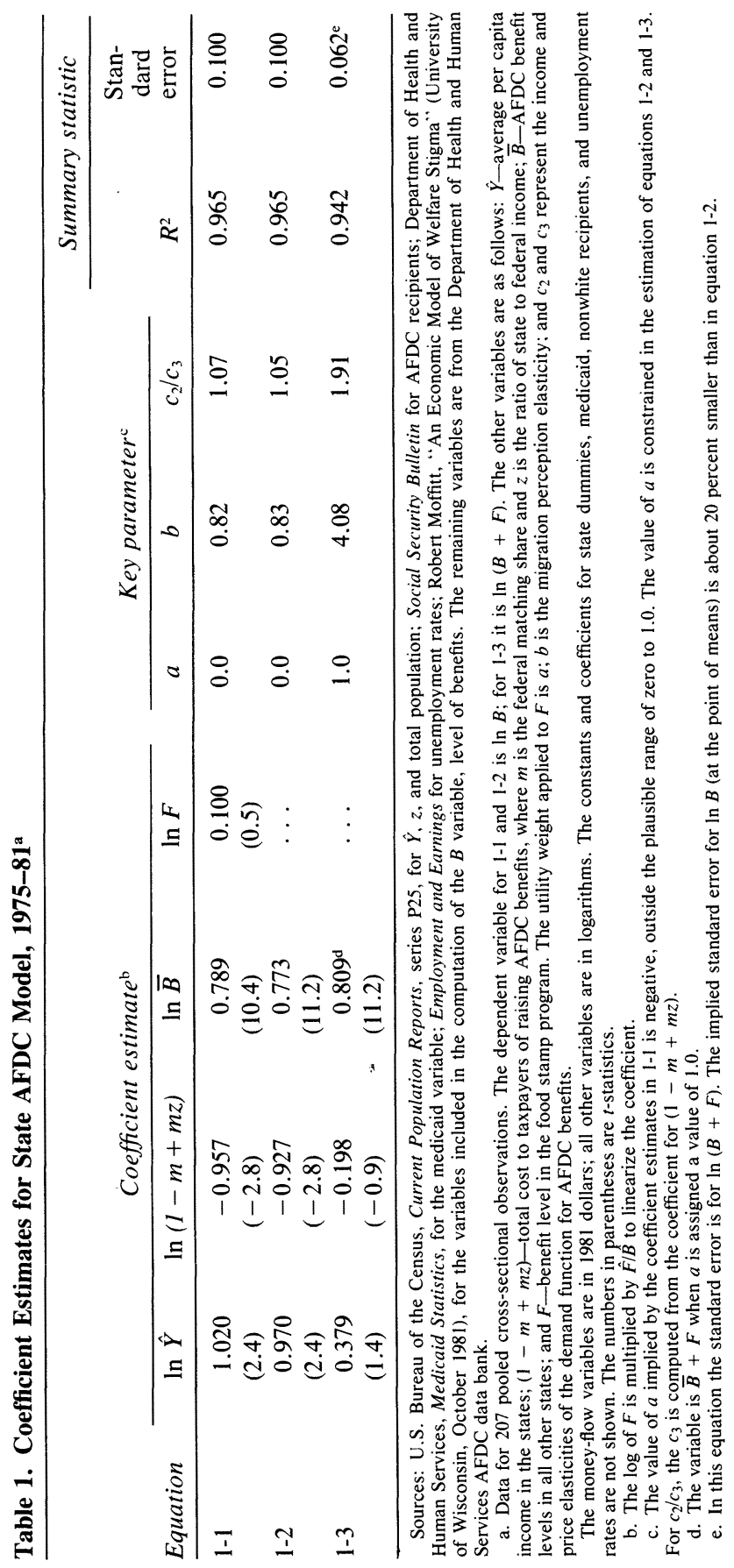


showed that federal open-ended matching grants can make expected state supplementation levels independent of state income when the income exponent, $c_{5}$, equals $c_{2} / c_{3}$. If that ratio is 1.0 , the formula for making state supplementation independent of income would become

$$
(1-m)=0.00004 \hat{Y},
$$

where $\hat{Y}$ is state per capita income and the constant, 0.00004 , is chosen so that the mean statewide federal matching rate equals the actual mean. The actual formula for state supplementation is

$$
\begin{aligned}
& (1-m)=0.45(\hat{Y} / \bar{Y})^{2} \text { for } 0.45(\hat{Y} / \bar{Y})^{2} \leq 0.5 \\
& (1-m)=0.5 \text { for } 0.45(\hat{Y} / \bar{Y})^{2}>0.5,
\end{aligned}
$$

where $\bar{Y}$ is national average per capita income. If the proper value for $c_{2} / c_{3}$ is near 2.0 , as is suggested by $1-3$, the ideal matching rate formula in Feldstein's sense requires $(1-m)=c_{4} \hat{Y}^{2}$, which would be very similar to the actual formula. If $c_{2} / c_{3}$ is near 1.0 , as suggested by the other two equations, the ideal matching rates differs from their actual values.

Table 2 compares actual with power-equalizing matching rates for the thirty-three states in the sample under the assumption that $c_{2} / c_{3}$ equals 1.0. The correspondence between actual matching shares and those necessary to make expected state-supplementation levels independent of state income is still reasonably good. Because the exponent is larger in the formula for actual shares, the variance of matching rates is higher than that in the computed power-equalization shares-Mississippi, for example, has an actual share of 0.233 and a computed power-equalization share of 0.296 .

Even though the open-ended grant formula equalizes fiscal power, it comes far from equalizing AFDC benefits across the country. One might then ask why Mississippi, a state with very low benefits, should have a rise in its price? Given the relatively low income-elasticity, Mississippi is here depicted as paying low AFDC benefits mainly because of preferences, and the impact of these preferences is not equalized by the computed federal formula. The present formula succeeds reasonably well in making expected state-supplementation levels independent of income, but that turns out to be a limited achievement. The way to reduce statewide variation in benefits, as stated above, would be to return to the kind of kinked AFDC matching formula that prevailed before states were induced to change to the medicaid formula. 
Table 2. Actual State AFDC Matching Share Compared to Value that Neutralizes Expected State Supplementation Levels

\begin{tabular}{|c|c|c|c|}
\hline State & $\begin{array}{c}\text { Actual } \\
\text { state matching } \\
\text { share, } 1981 \\
(1-m+m z)\end{array}$ & $\begin{array}{c}\text { Power- } \\
\text { equalization } \\
\text { value } \\
\text { if } c_{2}=c_{3} \\
(0.00004 Y)\end{array}$ & Difference \\
\hline Alabama & 0.299 & 0.335 & -0.036 \\
\hline Arkansas & 0.279 & 0.328 & -0.049 \\
\hline California & 0.553 & 0.492 & 0.061 \\
\hline Colorado & 0.475 & 0.455 & 0.020 \\
\hline Connecticut & 0.507 & 0.530 & -0.023 \\
\hline District of Columbia & 0.501 & 0.550 & -0.049 \\
\hline Florida & 0.437 & 0.410 & 0.027 \\
\hline Georgia & 0.349 & 0.366 & -0.017 \\
\hline Illinois & 0.525 & 0.469 & 0.056 \\
\hline Indiana & 0.441 & 0.394 & 0.047 \\
\hline Kansas & 0.470 & 0.444 & 0.026 \\
\hline Kentucky & 0.330 & 0.345 & -0.015 \\
\hline Louisiana & 0.325 & 0.387 & -0.062 \\
\hline Maine & 0.308 & 0.353 & -0.045 \\
\hline Maryland & 0.509 & 0.471 & 0.038 \\
\hline Massachusetts & 0.496 & 0.455 & 0.041 \\
\hline Michigan & 0.520 & 0.449 & 0.071 \\
\hline Minnesota & 0.454 & 0.439 & 0.015 \\
\hline Mississippi & 0.233 & 0.296 & -0.063 \\
\hline Missouri & 0.409 & 0.403 & 0.006 \\
\hline New Jersey & 0.516 & 0.494 & 0.022 \\
\hline New York & 0.538 & 0.467 & 0.071 \\
\hline North Carolina & 0.341 & 0.354 & -0.013 \\
\hline Ohio & 0.475 & 0.423 & 0.052 \\
\hline Oregon & 0.450 & 0.408 & 0.042 \\
\hline Pennsylvania & 0.477 & 0.423 & 0.054 \\
\hline South Carolina & 0.300 & 0.329 & -0.029 \\
\hline Tennessee & 0.320 & 0.351 & -0.031 \\
\hline Utah & 0.324 & 0.339 & -0.015 \\
\hline Virginia & 0.448 & 0.426 & 0.022 \\
\hline Washington & 0.509 & 0.460 & 0.049 \\
\hline West Virginia & 0.332 & 0.340 & -0.018 \\
\hline Wisconsin & 0.432 & 0.410 & 0.022 \\
\hline \multicolumn{4}{|l|}{ Addenda } \\
\hline Unweighted average & 0.421 & 0.412 & -0.009 \\
\hline Standard deviation & 0.090 & 0.063 & 0.039 \\
\hline
\end{tabular}

Sources: Same as table 1 . 
Migration Effects The third key behavioral variable is the migration perception parameter, $b$. Recalling the previous discussion, if $b$ is nonzero, either the perception of migration or emulation in general prevents states from raising their own AFDC benefits too far above those of their neighbors. The empirical results of table 1 indicate that the migration terms are always highly significant. When states are confronted with some exogenous change (such as a change in the matching rate) and the migration term is included in the calculation (as in a Cournot-Nash process), the long-run equilibrium change in benefits becomes much larger. Roughly the same is true in all other equations in table 1.

An objection could be that common trends in $\bar{B}$ and $B$ lead to this high coefficient on $\bar{B}$ and mistakenly give it causal significance. Since $\bar{B}$ gives a substantial weight to the average of $B$ in the current year, there is a simultaneity problem and the coefficient of $\bar{B}$ may be biased toward 1.0. Because of this possible bias, it is useful to compare the implied values of $b$, shown in the sixth column of the table, with direct estimates of $b$. Southwick's estimates referred to in note 17 clustered at about $1.0 .{ }^{27}$ If one had constrained the coefficient to the value implied by this independent estimate of migration effects, essentially the same results would have been obtained for the other parameters in 1-1 or 1-2.

To see how the Cournot-Nash process would work for the coefficients in 1-1, I simulated the impact of the new federalism proposals on state AFDC benefits. Turning AFDC over to states means essentially setting the federal matching share equal to zero. I assume this change was made in 1976, and compute steady-state percentage reductions in benefits by 1981. The first two columns of table 3 show actual 1981 AFDC-food stamp benefits $(B$ and $B+F)$ for families with standardized levels of outside income, in 1981 dollars. Combined benefits average $\$ 396$ a month, with a standard deviation of $\$ 80$. The predicted long-run percentage changes from equation 1-1 if other states are assumed not to change their benefits are given in the third column. The reduction of $m$ to zero raises the price of AFDC to states by an average of about 75 percent, and lowers benefits by an average of 56 percent, with a standard

27. Southwick, "Public Welfare Programs." I got this from his test 5, where he finds that a 10 percent increase in $B$ increases in-migration of welfare recipients by 25 percent. Since migrant welfare recipients in a census region are about half the total, total $R$ rises by roughly the same proportion as $B$. 
Table 3. AFDC Benefits and Percentage Reductions Eliminating Federal Matching ${ }^{a}$

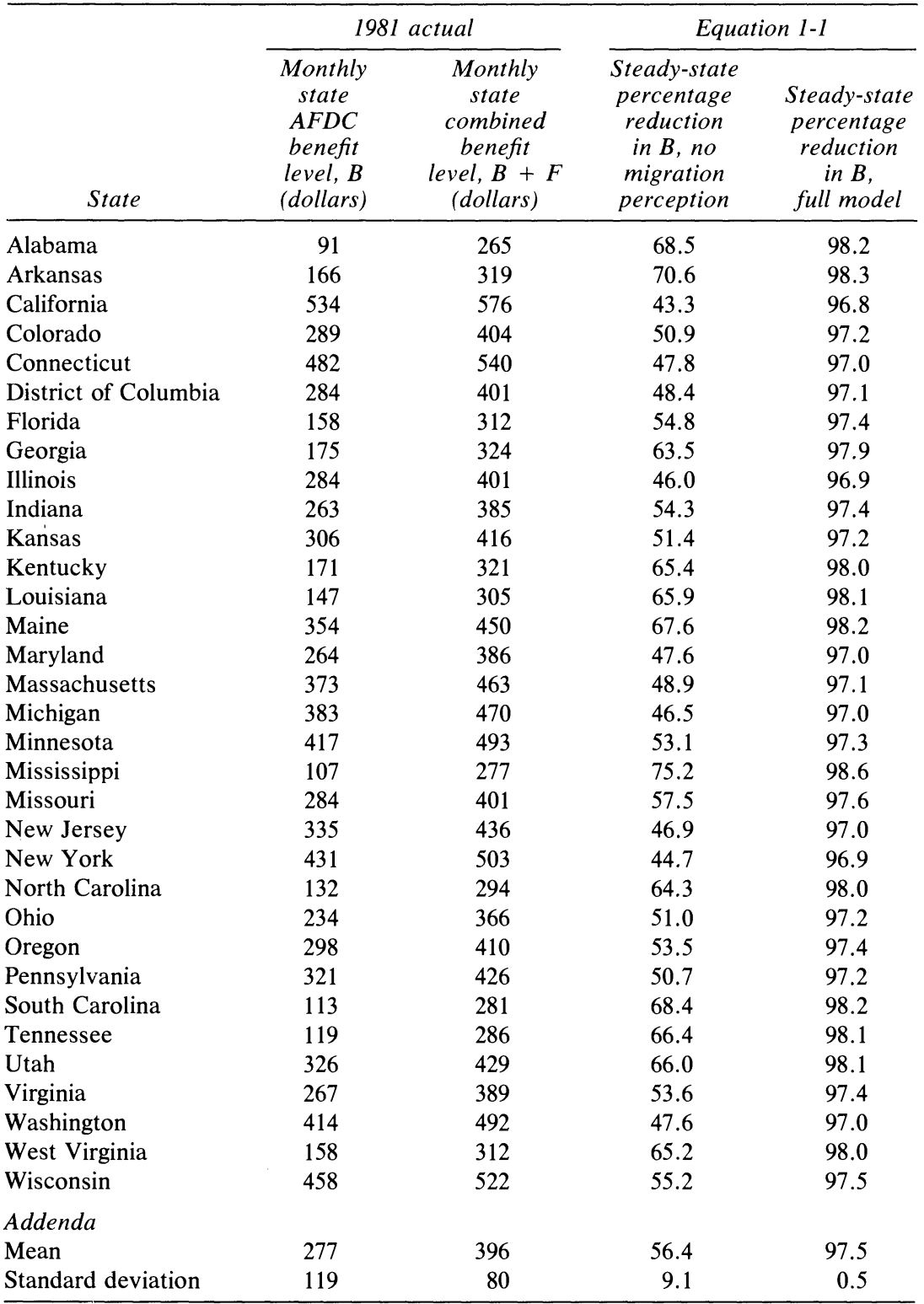

Source: Same as table 1 and author's calculations.

a. The federal matching share is assumed to become zero in 1976, and the corresponding reductions in benefits are computed for 1981. The benefits shown are for families with standardized levels of outside income as described in the text. 
deviation of 9 percent. This is a large reduction in and of itself. But when other states are allowed to respond, as in a full dynamic simulation of that equation with all states endogenous, benefits are reduced by an average of nearly 98 percent, with a standard deviation of less than 1 percent. The reason the mean percentage reduction rises so much is the multiplier due to the series of Cournot-Nash interactions. The reason the standard deviation actually declines is that the initial responses are more disparate because the price changes are uneven across states, but when the Cournot-Nash reactions are added, all states are subject to similar demonstration effects.

\section{THE INCOME-SUPPORT SYSTEM}

Each of these key parameter estimates illustrates an important characteristic of the current hybrid AFDC-food stamp system. The first two estimates show the system in a reasonably favorable light. Since $a$ appears to be close to zero, it is not only possible for the federal government to impose a floor of $F$ under combined benefits, $B+F$, but to make marginal changes in this floor without offsetting changes in $B$ (which would obviously not be true if $a$ were 1.0). The same coefficient indicates that combined benefits depend greatly on whether food stamps will remain as a federal program or shifted to state responsibility. As indicated in discussing the empirical results above, the estimate that $a$ equals zero on which these inferences are based is not offered with great confidence. Any inferences about major changes in federal support would be made with more confidence if they could be based on data from periods when food stamps were varying more in real terms.

The estimated income and price elasticities suggest that power equalization-matching shares are not far from the state matching shares now contained in present law, implying that state supplementation levels are approximately independent of state income. But statewide benefits still vary widely. This shows that neutralizing income-induced disparities in benefits accomplishes little in the way of equalizing AFDC benefits across states. Apparently the only way benefits can be significantly equalized within the present grant structure is by reintroducing the kinks in the AFDC formula that were allowed to evaporate with inflation and the introduction of the medicaid formula for AFDC reimbursement.

One parameter estimate points out an unfavorable aspect of the 
current system. The migration or emulation parameter is so large that state supplementation levels are clearly dependent on those in other states. As long as states set benefits in an uncoordinated manner, these supplementation levels do not reflect the unconstrained preferences of legislators in different states, and thus do not indicate state voter preferences. Moreover, they can lead to a highly unstable response pattern when pervasive exogenous changes are made in federal policy, such as the proposed reduction in federal matching rates.

The obvious programmatic remedy for the latter two problems would be to move toward a more nationalized determination of AFDC benefits, with a higher federal floor on benefit levels or with nonlinearities in federal matching shares that would reduce the variance in benefits among states. The original administration proposal, in attempting to decentralize determination of both AFDC benefits and food stamps, appears to move in exactly the wrong direction. But if the administration agrees to a "compromise" in which food stamp guarantees are continued as a national program, and in which a minimum is built into the AFDC program (as eight former Secretaries of the Department of Health, Education, and Welfare proposed in September 1982), there would be movement in exactly the right direction.

\section{Should Categorical Grants Be Continued?}

The other significant change proposed by the president is to eliminate most of the restrictions on federal categorical grants. This happens in various ways. Last year Congress, acting on the president's initiative, converted fifty-seven categorical grant programs to block-grant form, with much less restrictive spending conditions on state and local governments. This year another forty-one categorical programs are to be consolidated, implying a total switch of $\$ 14$ billion to block-grant form. In 1984 the president proposes to take all the block grants created under President Nixon, those created in his own administration, general revenue sharing, and still more categorical funds and throw them all into a giant trust fund that in effect forms a block grant for the whole package. At the end of the decade financial responsibility for operating the trust fund reverts to state governments, and in any realistic sense the categorical grant programs have been killed. The long-run budget plan of the 
administration lists only $\$ 25$ billion in categorical grants by the end of the decade, less than one-third of the level at the start of the Reagan presidency.

The details of this plan are still being negotiated with state governments and it is too early to know just what the outcome will be. Even if it were not too early, it would be very difficult to put a tracer on all the programs and all the money, and that is not what I propose to do here. What I do instead is use a model of the state and local budget process to appraise the general suggestions raised by the president-loosening strings on federal grants and cutting back on the federal money. The way in which this is done is to examine, using time-series data on state and local government aggregates, how the state and local sector responded to past changes in grants and other variables and, within this model, how it seemed to respond to earlier block grant initiatives made by President Nixon.

The model used to examine these effects is essentially the one employed in my 1978 article attempting to explain the mysterious rise in the state and local general government budget surplus. ${ }^{28}$ That model derives a set of demand equations for different types of expenditures, taxes, and the budget surplus from orthodox utility-maximization principles and estimates the model subject to the budget identity constraints. The model allows for grants with different categorical restrictions to have different effects on state and local fiscal responses, and also for stock-flow adjustment behavior in which short-term changes in grants can influence the surplus (as they appear to). But once stocks of financial and physical assets have been accumulated to their target level, changes in the surplus and net physical investment cease, and all changes are equally reflected in noninvestment expenditures and revenues.

The new model adheres to this spirit closely with only a few changes. Because I am now interested in the impact of categorical or block grants on the normal public goods expenditures of state and local governments, I disaggregate budget expenditures into AFDC transfers (which have already been dealt with in the previous section and will not be attended to further here), construction (which, as the 1978 article pointed out, is almost impossible to explain using standard economic type variables and is largely unaffected by the 1982 proposed changes in grant catego-

28. Gramlich, "State and Local Budgets." 
rizations), and all other current expenditures of state and local general governments. This section focuses on this last category of expenditures, which I will call public consumption purchases. Since I am particularly interested in the proposed conversion of categorical to block grants, I then disaggregate federal grants aimed at supporting public consumption purchases into their categorical and block components, estimating separate coefficients for each. The first of the three important block grants, for social services, appeared in 1972; the next, created by the Comprehensive Employment and Training Act (CETA), in 1975; and the last, Community Development Block Grants (CDBG), in 1976. To derive sensible coefficients it was necessary to extend the regression period through 1981, and because quarterly flows of these grants are not available, I was forced to estimate the model with annual data from 1946-81. Finally, to impose the cross-equation coefficient restrictions, I estimated the model with a regression technique that incorporates the budget identity restrictions, permits different autocorrelation corrections for different equations, and allows for systematic correlations between contemporaneous residuals in different equations.

Comparing the first and second parts of this paper, both the first part explaining AFDC benefits and the second part explaining public consumption use an underlying utility-maximization framework. In both parts a key question involves displacement of a federal grant. In the first part, that question is whether AFDC benefits will be reduced in response to food stamp increases, and of course the mirror-image question of whether benefits will rise if the Reagan administration succeeds in cutting out food stamps. In the second part the displacement issue involves present categorical grants that support public consumption. Do these grants simply allow states and localities to reduce their own expenditures in an area, or do they add to total spending? Then, if the Reagan administration succeeds in converting these grants to block grant form in which they are largely converted to cash, will spending go down, and by how much?

Beyond this central unity of question and technique, there are also some differences between the two parts of the paper. The first part takes a very detailed look at one fiscal component, AFDC expenditures, and leaves all other types of expenditures (public and private) in a broad catchall group, $X_{i}$. The second part contains a less detailed look at its primary focus, public consumption, and disaggregates the $X$ vector into 
four other categories. Further, since the first part involves mainly price and income elasticities, the implied central spending equation is assumed to be logarithmic. But in the second part the central question involves the block-grant conversion, and because these block-grant terms should work in linear fashion with linear state budget identity constants built into the estimates, the implied central spending equation is assumed to be linear.

Five equations-for public assistance, construction, public consumption purchases, taxes, and the surplus-were estimated simultaneously, with a few trials on the zero restrictions for various independent variables that had insignificant or puzzling coefficients in different equations. The equation for public consumption purchases, the main object of interest here, had sensible coefficients in almost all trials, while some other equations, such as construction, performed poorly. ${ }^{29}$ To spare the reader a mass of numbers, I present only equations for public consumption purchases. Three variants are given in table 4 . The variant in the second row drops some of the independent variables with insignificant or apparently incorrect signs somewhere in the coefficient matrix; and the variant in the bottom row drops almost all insignificant or incorrect signs in the coefficient matrix. It can be seen that the fit of the public consumption equation is always quite good, and the coefficients on the most important variables change relatively little as more and more zero restrictions are made on the coefficient matrix. The best equation for public consumption purchases (as opposed to the whole budget system) is clearly the first-it fits much better than the others, and its coefficients are always more sensible.

The dependent variables in these equation systems are discretionary expenditures, expenditures on the relevant component minus those expenditures mandated by categorical or block grants. To ensure that the partial derivatives show how total public consumption purchases respond to grants of various types, it is necessary to add back mandated expenditures. The partial derivatives and elasticities once this is done are shown in table 5. In the first, and probably best, equation, a dollar's

29. For what it is worth, the equation for AFDC transfers was fairly consistent with the results in the first part of the paper. As was the case there, both income and price coefficients implied absolute elasticity values somewhat below unity. Other important questions, such as the impact of food stamps and benefits in other states, were omitted from the model used in the second part. 


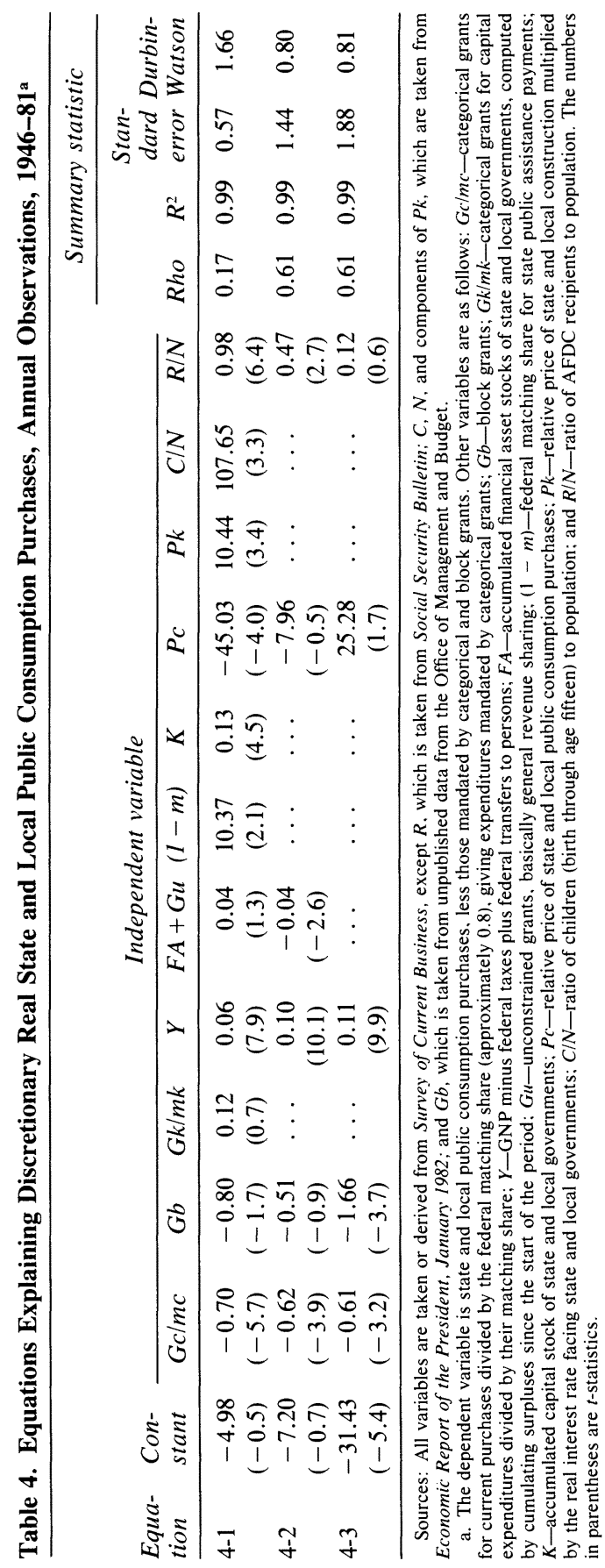


worth of categorical grants (with a federal matching share averaging its actual value of 0.8$)^{30}$ is seen to stimulate $\$ 0.38$ worth of state and local public consumption expenditures. This apparently low value results from the fact that discretionary expenditures depicted in table 4 react with a significantly negative effect to categorical grants (as indicated in table 4), reflecting what has come to be known as the grant displacement, or fungibility, effect. This effect is, not surprisingly, even stronger with the less constrained block grants: here a dollar's worth of block grants stimulates only $\$ 0.20$ worth of state-local public consumption. A dollar increase in private income stimulates $\$ 0.06$ of state-local public consumption (the implied income elasticity being 0.63 , a consensus number for studies of state-local behavior), and a dollar of unconstrained grants such as revenue sharing stimulates $\$ 0.04$ worth of state-local public consumption. The relative size of the latter two numbers is somewhat surprising in light of a recent debate about the so-called flypaper effect: even though unconstrained grants and income should theoretically have the same effect on state-local public consumption, in many other studies unconstrained grants have been found to have a stronger effect to the extent that "money sticks where it hits." ${ }^{11}$ In these equations there is no flypaper effect.

The responses shown in table 5 indicate that switching $\$ 14$ billion from categorical grants to block grants, as the Reagan administration has proposed to do for the 1983 budget, will lower state-local public consumption purchases by $\$ 2.5$ billion, a drop of less than 1 percent from levels likely to be in force in that year. Were the entire shift made, about $\$ 10$ billion will be transferred from block grants to unconstrained grants and another $\$ 20$ billion from categorical grants to unconstrained

30. These matching shares can be computed from numbers given in OMB, Special Analyses, Budget of the United States Government, Fiscal Year 1982, p. 255. The overall ratio mentioned there was adjusted to remove the influence of block and unconditional grants (for which there is no matching) and grants to individuals (for which, as was shown above, the federal share is about 0.58 ).

31. The flypaper term was originally coined by Arthur Okun when he edited the precursor to this part of the paper ten years ago. Reasons for it were debated rather extensively in Peter Mieszkowski and William H. Oakland, eds., Fiscal Federalism and Grants-in-Aid (Washington, D.C.: Urban Institute, 1979). For what it is worth, the longterm effect of income on public consumption is just about $\$ 0.06$, virtually the same as the impact effect, while the long-term effect of unconstrained grants is $\$ 0.18$. But this larger long-run effect should certainly not be attributed to flypaper, which is mainly a short-run phenomenon. 
Table 5. Key Response Parameters, State and Local

Public Consumption Purchases

\begin{tabular}{|c|c|c|c|c|c|c|c|c|c|}
\hline \multirow[b]{2}{*}{ Equation } & \multicolumn{4}{|c|}{ Partial derivatives } & \multicolumn{2}{|c|}{ Elasticities $^{\mathrm{a}}$} & \multicolumn{3}{|c|}{$\begin{array}{l}\text { Willingness to pay } \\
\text { to eliminate restrictions }\end{array}$} \\
\hline & $Y$ & $G u$ & $G c$ & $G b$ & $Y$ & $P c$ & $\begin{array}{l}\text { Categor- } \\
\text { ical to } \\
\text { block }\end{array}$ & $\begin{array}{l}\text { Block } \\
\text { to uncon- } \\
\text { strained }\end{array}$ & $\begin{array}{c}\text { Categor- } \\
\text { ical to } \\
\text { uncon- } \\
\text { strained }\end{array}$ \\
\hline $4-1$ & 0.06 & 0.04 & 0.38 & 0.20 & 0.63 & -0.50 & 0.01 & 0.01 & 0.02 \\
\hline $4-2$ & 0.10 & -0.04 & 0.48 & 0.49 & 0.97 & -0.09 & 0.00 & 0.13 & 0.13 \\
\hline $4-3$ & 0.11 & 0.00 & 0.49 & -0.66 & 1.07 & 0.27 & c & c & c \\
\hline
\end{tabular}

Source: Computations based on table 4 .

a. At point of means.

b. For conversion of $\$ 10$ billion of grants at 1978 values of prices and expenditures

c. Not computed because the estimated price elasticity has the wrong sign.

grants, lowering state-local public consumption by $\$ 8.4$ billion, a drop of slightly over 2 percent from levels that would otherwise be in effect at the time. Although there may be significant changes in expenditures for particular programs, the overall reductions are not large, clearly not the stuff of fiscal revolutions. They are small first because for all the rhetorical trumpeting of the growth of categorical grants, these grants are still quite small relative to state-local public consumption expenditures; and second because, as the coefficient estimates suggest, there already appears to be a great deal of displacement for categorical grants.

The final numbers in table 5 display the grant coefficients in a different way. The expenditure responses indicate that categorical grants have generally stronger impacts on the state-local public consumption than do block grants, presumably because many of the strings on grants are untied, and that block grants have stronger impacts on public consumption than do unconstrained grants, because not all the strings on block grants are untied. When the Reagan administration made its first proposal for converting categorical grants to block grants, it reduced these grants by 25 percent. Somewhere in OMB there could have been a calculation that states and localities would be willing to pay, or forgo, 25 percent of the grants to have some of the strings untied. The last three columns in table 5 show, for the three estimated equations, how much of categorical grants states should be willing to forgo to have a categorical grant converted to block-grant form, to have a block grant converted to an unconstrained grant, and to have a categorical grant converted to an unconstrained grant. These calculations are done by locating states' 1978 equilibrium points under the grants being compared with the 
responses shown in table 5, using the price elasticity to measure the change in the slope of the indifference curve over the interval, and using trigonometric identities to determine how far along the income (or blockgrant) consumption line states would have moved on the lower indifference curve intersecting the constrained grant equilibrium point.

The willingness-to-pay calculations show that in the first equation, which performs best, states are already able to divert categorical funds to their own purposes to a sufficient degree that they would be only willing to forgo 1 percent of these grants to have them converted to block-grant form. According to these calculations, the OMB cut in funds of 25 percent was much too large to leave states as well off. Even block grants have some strings, so states should be willing to sacrifice another 1 percent of the block grants to have them converted to completely unconstrained grants such as general revenue sharing. According to the second equation, the response to block grants and categorical grants is identical; states would not be willing to sacrifice at all to have the strings removed, and again, OMB cut grants too much in 1981. But since block grants have a larger spending impact than unconstrained grants, and because the price elasticity is lower in this equation, states would be willing to sacrifice 13 percent of their categorical or block grants to have them converted to unconstrained grants.

Whether one looks at expenditure responses or willingness to pay, the inescapable conclusion is that this component of the new federalism is much ado about nothing. Most of the response estimates indicate that there is already a high degree of displacement for categorical grants, implying that those strings now on these grants to persuade states to spend the grant money are relatively ineffective. Removing these strings will not cause any great social losses, but there will not be large improvements, either. According to the estimates given here, there will be relatively minor changes both in state-local public consumption purchases and utility levels as a result of the president's proposed changes.

\section{Conclusion}

This analysis suggests that some parts of Reagan's new federalism program will make an enormous difference on state-local spending levels, and some parts will make little difference. In general, the proposals 
involving income-support policies will make a great difference. Increasing the marginal cost of AFDC benefits for all states will lower benefits because of the normal price effect, and then lower benefits further to the extent that state responses are a function of the uncoordinated responses of other states. Decentralizing food stamps would also greatly reduce combined benefits for recipients, if it is correct that states decide on AFDC levels independently of food stamp levels and do not replace any federal cutbacks. But one measure that appears to make very little difference, at least on expenditure levels, is the conversion of categorical to block grants. The reason for this is that states already appear to be responding to categorical grants with so much freedom, or spending so much less than the grant provisions require, that an elimination of these strings should not have terribly large effects on either public consumption levels or state utility levels. 


\section{Comments and Discussion}

Henry J. Aaron: Edward Gramlich has made a valorous attempt to provide convincing estimates of the effects on state welfare spending of President Reagan's proposal to shift responsibility for food stamps and AFDC to the states in exchange for federal assumption of medicaid costs. If, in the end, I find his estimates unpersuasive, it is more because of the recalcitrance of the data with which he is forced to work than with any shortcomings of his methods.

Before turning to his paper, it is useful to look back on the trends in expenditures with which he is concerned. Table 1 of these comments presents information on real expenditures in billions of 1979 dollars over 1970-79 by both federal and state governments under AFDC, medicaid, food stamps, and supplemental security income (SSI). The table also contains information on total state expenditures for selected aggregations of assistance programs and for total state and local spending.

Table 1 reveals striking contrasts. Growth in total state spending slowed markedly in the late 1970 s and reached a peak in 1978, as did state spending on welfare-type programs. AFDC spending reached a peak in 1976 and has been declining since then. Expenditures on food stamps rose sharply and without interruption during this period, largely because the number of recipients increased. Medicaid expenditures have risen continuously, mainly because of rising medical costs. Both federal and state SSI expenditures have declined since 1976 because of declines in the number of aged recipients only partly offset by growth in the number of disabled beneficiaries and because state supplements have been permitted to decline in real value.

Table 2, compiled from the data in a paper by Richard Kasten and John Todd, shows what has happened to average maximum AFDC 


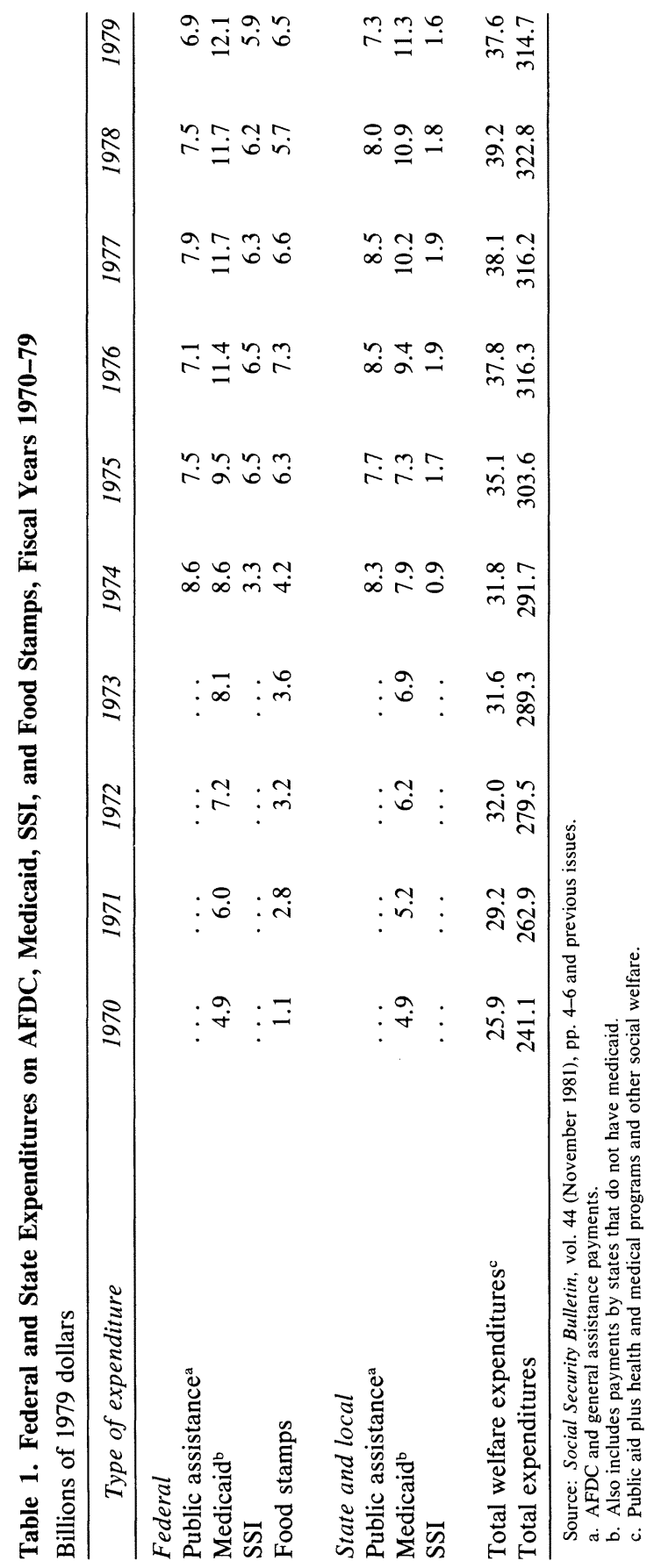


Table 2. AFDC and Food Stamp Benefits, 1969-79

Dollars per month (1979 prices)

\begin{tabular}{cccc}
\hline Year & $\begin{array}{c}\text { Average } \\
\text { maximum } \\
\text { AFDC }^{\mathrm{a}}\end{array}$ & $\begin{array}{c}\text { AFDC } \\
\text { and } \\
\text { food stamps }\end{array}$ & $\begin{array}{c}\text { Food stamps } \\
\text { (residual) }\end{array}$ \\
\hline 1969 & 445 & $\ldots$ & $\ldots$ \\
1970 & 438 & $\ldots$ & $\ldots$ \\
1971 & 440 & $\ldots$ & $\ldots$ \\
1972 & 435 & $\ldots$ & $\ldots$ \\
1973 & 426 & $\ldots$ & $\ldots$ \\
1974 & 414 & 520 & 106 \\
1975 & 403 & 511 & 108 \\
1976 & 398 & 500 & 102 \\
1977 & 391 & 486 & 95 \\
1978 & 380 & 477 & 97 \\
1979 & 361 & 478 & 117 \\
\hline
\end{tabular}

Source: Richard A. Kasten and John E. Todd, "Transfer Recipients and the Poor During the 1970s," paper presented to the Second Research Conference of the Association of Public Policy Analysis and Management (Boston, October 1980).

a. Benefits paid to recipients with no outside income.

benefits (that is, benefits paid to recipients with no outside income) and to combined food stamp and AFDC benefits. The table shows that AFDC benefits have fallen sharply in real terms, and that even after food stamp benefits are added, the average maximum payment to families eligible for both programs has declined.

Under one interpretation, the growth of food stamps has reduced the perceived need for cash assistance and led states to reduce AFDC benefits. Under this interpretation, one need not look at other aspects of welfare expenditures, unless they too affect perceived needs of AFDC recipients or the overall fiscal position of the state. Gramlich has modeled this possibility and allowed the data to determine the extent to which states let food stamps substitute for AFDC payments.

There is another interpretation for what has been going on. For the past several years, states have been fiscally distressed. Under the multiple blows of slowed economic growth and of tax expenditure limitations, which may reveal changes in voters' tastes about public spending, they have slowed the growth of public spending in general, and of redistributive expenditures in particular. The increases in medical costs, uncontrollable by individual states, have contributed to medicaid claiming an ever larger share of state budgets. States could offset this tendency directly only by legislative deliberalizations in benefits or 
coverage. But states have been helped by the acceleration of inflation to offset them indirectly by letting fixed nominal AFDC payment levels gradually devalue.

So one can view these trends as the rational, utility-maximizing response of states to the advent of a new federal program, from which one can infer the substitutability of food stamps for cash benefits. Or one can view these trends as the disequilibrium response of state governments to changes in prices, incomes, and preferences, in which case nothing can be inferred, I think, about the substitutability of food stamps for cash benefits.

Gramlich has assumed the utility-maximizing approach. His model posits that the sum of an index of welfare benefits and a multiple of food stamp benefits is gradually moved by states toward a desired level that is a function of mean per capita income in the state; the price per dollar of AFDC expenditures, based on the state matching share; the proportion of the state population that received benefits; the level of welfare benefits in surrounding states and in the nation as a whole; and a vector of other variables. It is unfortunate that the data limitations that Gramlich describes prevent him from adequately modeling medicaid payments, which he indicates he would, in principle, include in the utility function and which I suspect may have a lot to do with total state welfare spending. I return to this below.

The variable used to specify the generosity of state welfare payments is a function of the state's guarantee at zero income and the implicit tax rates on earned and unearned income. One could quibble over this measure-for example, it contains no measure of administrative procedures that affect take-up, and it is based on fixed values for each state of the tax variables and of earned and unearned income-but I think that, as a practical matter, it would be rather difficult to make much of an improvement.

The composite variable measuring the subjective value to state officials (or voters-the utility-maximizing unit is not altogether clear) of the sum of AFDC and food stamp benefits depends on the weight assigned to food stamps. Gramlich obtains an estimated weight of zero in the regressions he prefers, but shows that an alternative estimating equation produces an estimate near 1.0. Thus he acknowledges a good deal of uncertainty in his estimates of this key parameter. A simple test of the predictive value of the model, and one that might help pin down 
this parameter, would be to use it to "backcast"- that is, to predict AFDC benefits for earlier years than are included in the sample. It might be necessary to use some period before the transition to food stamps began.

I believe that there is a more basic problem with this model, however, one that emerges from an examination of the way in which medicaid expenditures enter the analysis. With admirable consistency, Gramlich develops a framework within which some entity maximizes utility by paying AFDC plus food stamps to AFDC recipients, subject to a net income budget constraint. In this spirit, one is interested in knowing how much less such an entity will pay in cash plus food stamps if these same beneficiaries receive a certain amount of medicaid benefits.

As I indicated above, Gramlich does not treat medicaid symmetrically with the other benefit programs because the data are inadequate. Nonetheless, I believe some attempt should have been made to introduce medicaid spending into the estimation. If, as I suspect, the growth of total medicaid costs has been a factor in heightening sensitivity to the burden of welfare broadly defined, one needs to include some variable to take account of its growth. Lacking any more carefully crafted measure, I would include state-financed medicaid expenditures divided by total state population as a reasonable proxy.

In addition, however, if states have a notional subbudget for welfaretype expenditures, one would have to include the effects on state expenditures of federal assumption of the state medicaid share in order to obtain a complete estimate of the effects of the Reagan program on state welfare outlays. Within Gramlich's framework, it would be possible to measure the effect on the state tax rate and, hence, on net income of reducing state expenditures on medicaid to zero.

A related difficulty is the likelihood that preferences have changed regarding public expenditures in general, and welfare or redistributive expenditures in particular. I know of no satisfactory way to deal with this problem. One is tempted to suggest the use of dummy variables for the enactment of tax spending limitation; but this approach suffers from problems too obvious to enumerate. Data in my table 1 document a significant falling off in state welfare-type expenditures. If preferences have changed significantly, a serious shadow falls over the entire approach in this paper.

The results of Gramlich's table 3 raise other questions. The changes 
in benefit levels, if one impounds the effects of fears of migration, average a little over 50 percent, with suitable diversity among the states; but if the migration perceptions, on which the model is predicated, come into play, benefits will be reduced by almost exactly the same, very high proportion in every state. On the general principle that there must be something wrong with any model that predicts all fifty states will respond to anything in the same absolute amount or in the same proportion, I turn to the final section of the paper.

It contains reestimates of a model first presented several years ago. These estimates are used to estimate the effect of President Reagan's proposal first to convert most categorical grants to block grants and then to eliminate them. I have no comments on this section, other than to express my regret that results for public assistance were not presented in addition to those for public consumption. If they had been presented, one could have compared the estimates of the effect on welfare expenditures of the swap of federal assumption of medicaid costs from the first part of the paper with results from this more comprehensive model. The federal assumption of all medicaid costs, in effect, is the reduction of a categorical grant linked to an increase in general revenue sharing. The state assumption of the costs of AFDC and food stamps, in effect, eliminates two categorical grants. But since Gramlich's tables 4 and 5 report results only for public consumption, the reader is prevented from linking up the first and second parts of the paper.

I only wish that I found Gramlich's econometrics more persuasive, as he ends at a position I find most congenial, the judgment that the Reagan initiative will result in sizable reductions in local expenditures, both as a result of incentive effects and because the cuts in spending outweigh the estimated utility gains from increased flexibility. Public debate should focus on this effect of the proposed initiative, rather than on the supposed tidying up of the responsibilities of different levels of government, and Gramlich characteristically directs us to keep our eye on the right ball.

Michael C. Lovell: Because it has been only eight months since President Reagan presented his program for the new federalism, the analysis presented in this paper obviously constitutes fast work. Nevertheless, it is a thoroughly researched and skillfully executed study that is certain 
to be recognized in its own right as an important contribution to knowledge, regardless of the fate of the Reagan proposals.

To my mind, the most provocative result advanced in this paper has to do with the strength of the migration effect on state-determined benefit levels. Legislators apparently fear that their states will be inundated by an influx of recipients, and perhaps an outflow of taxpayers, if their welfare programs are more generous than those of neighboring states. The impact is summarized in table 3 . It presents estimates indicating that, if legislators were not concerned about migration, the elimination of federal matching for the aid for dependent children (AFDC) program would result in benefit cutbacks averaging 56 percent; but because legislators fear migration, as Gramlich's estimates say they do, AFDC benefits will be almost eliminated. This is a strong conclusion about the consequences of a downward spiral of benefits analogous to oligopolistic price wars. Although I am not convinced by these estimates for reasons I explain below, I want to emphasize that I am impressed by Gramlich's demonstration that this conclusion is compatible with the available data.

It may be worth noting that Gramlich's conclusion does not rely on an analysis of political machinations, such as the back-scratching activities and pressures of agricultural interest groups that have influenced the federal food stamp program. And Gramlich does not rely on an attempt to model the forces of single-issue voters on legislators, the incidence of log-rolling activities in state capitals, and so forth. Nor does the analysis rest on an attempt to measure directly the extent to which people actually migrate from one jurisdiction to the next in a quest for higher welfare benefits. Further, the perceptions of politicians are not measured through the use of survey techniques, which is just as well; I suspect that many legislators answering a poll would be inclined to emphasize migration in attempting to rationalize niggardly support for welfare programs, whatever the true reason for their position.

In deciding whether Gramlich's conclusion should be accepted, one must consider the structure of the model of the political process that he uses and the appropriateness of the variables he incorporates in its empirical implementation. Gramlich presents evidence on the variations in levels of state aid that result from differences among states in federal matching rates for the AFDC program, variations in state income, case load, and so forth. He proceeds by assuming that the legislative outcome 
is determined by a "decisive voter" maximizing his (or her) utility function. The decisive voter plays a role as central to Gramlich's analysis as the "representative firm" did to the analysis of Alfred Marshall. Perhaps the "decisive voter" is Harold Hotelling's "median voter"; perhaps not.

I believe that Gramlich's estimates may be biased by the omission of a critical variable. My candidate variable comes from considering the determinants of the tax price paid by the decisive voter. If we were to work through the analysis carefully, I suspect the tax price will be found to depend critically on the ratio of the decisive voter's income to average income. If in fact the decisive voter is Hotelling's median voter, it is the ratio of median to mean income that is critical. This skewness variable has worked in my own research on variations among school districts in education expenditures; I think a measure of skewness of each state's income distribution might be even more important in explaining differences in welfare expenditures.

It may also be important in evaluating state versus federal financing to note that state expenditures, in addition to direct matching from Uncle Sam, are indirectly matched in the case of voters who itemize their deductions. Consider voters living in an average state who find themselves in the 35 percent tax bracket. An increase of $\$ 1$ in per capita spending at the federal level will impose a $\$ 1$ incremental tax burden (ignoring progressivity). Although a $\$ 1$ increase in expenditures in these voters' home state will also result in a gross increase of state taxes of $\$ 1$, 35 cents of the dollar will be offset by a reduction in the federal income tax due to the deductibility of state and local taxes. The tax price paid by voters who itemize therefore may be only 65 cents of taxes per marginal dollar of state expenditure. While Uncle Sam may have to raise taxes to offset this loss of 35 cents, this is almost negligible at the margin for voters who itemize because it is spread out among taxpayers throughout the fifty states. While it is true that only about 30 percent of federal taxpayers itemize, which means that the "median taxpayer" takes the standard deduction, it is at least conceivable that state legislators, given their own tax brackets, may be more attuned to the interests of itemizing taxpayers. Thus it seems to me at least conceivable that a relinquishment of traditional federal responsibilities to the states might raise total government spending, other things remaining equal.

Although I have not been fully convinced by Gramlich's estimates of 
the effect of migration perception on legislators, it is worth thinking a bit more about its possible consequences. First of all, I would not be surprised if an evaluation of the utility function underlying Gramlich's analysis revealed that the fall in average AFDC benefits caused a marked reduction in the utility levels of the decisive voter in every state. If this is so, it is not necessarily an argument for federal financing, for it would be possible for states to collude with their neighbors to establish appropriate benefit levels in order to avoid the migration threat. In contrast to oligopolistic firms, states are free to collude without the fear of antitrust prosecution. And such collusion would be mutually beneficial, not just to the colluding state legislatures and administrators, but to each state's "decisive voter" as well.

Finally, I must mention that in evaluating the redistributional implications of the Reagan administration's new federalism, it is important to consider more than the impact of the proposed shift of responsibilities on the level of benefits paid in the various states, as in table 3. It is also necessary to consider the redistribution of the financial burden. For example, a wealthy state paying more taxes per capita to the federal government and receiving less in federal support than poorer states would find the self-financing of AFDC relatively easy. To illustrate, Connecticut had about 8 percent of its school-age children living below the poverty level in 1975 while Mississippi had 32.3 percent. The federal personal tax burden for Connecticut residents averages about two and one-half times the tax burden for residents of Mississippi. Shifting the financing of the AFDC program to the states will impose a heavy tax burden on precisely those states that do not have an adequate tax base to shoulder the burden. Not just the poor, but also the poorer states have much more to lose than the rich from the Reagan proposals. It would be useful in evaluating the likely political future of the new federalism proposals to know which states will gain and which will lose.

\section{General Discussion}

George Perry disagreed with Michael Lovell's emphasis on the deductibility of federal taxes. He reasoned that deductibility did not change Gramlich's formulation in an important way because it would be present both before and after the AFDC program was turned back to the 
states. If the median voter deducted his share of the state's welfare expenditures before the reform, he would deduct his share of the state's presumably higher welfare expenditures after the reform as well. Lovell responded that Perry is assuming that voters at the state level were taking responsibility for these programs, at least at the margin, before the change in federal financing. If voters in fact view these programs as a new responsibility as a result of the change in financing, then Perry's argument would not be relevant. Joseph Pechman stressed a point that Lovell had passed over lightly: the deductibility of state and local taxes is irrelevant for the median voter because the great majority of federal taxpayers do not itemize deductions. Roger Gordon pointed out that the voter's conception of tax cost might be complicated in a different way. A large share of state and local revenues are raised by taxes on commercial and industrial property. The median voter may not regard himself as paying this portion of the tax. To the extent that different states have differing amounts of this type of property to tax, the median voters across different states may face substantially different tax prices of raising AFDC benefit levels.

Alan Blinder wondered about the implications of Gramlich's results for other dimensions of state behavior. Given the large amount of cyclical variability in economic conditions over the period under study, he suggested that states facing bad economic times might have tried to force poor people off welfare rolls. Gramlich responded that the coefficients on state per capita income and unemployment rates did show such effects in state behavior.

Michael Wachter observed that the most common response of state and local officials to reduced federal funding is not reductions in benefits but greater stringency in applying eligibility criteria. This impact is terribly difficult to detect using the econometric techniques in Gramlich's paper. $\mathrm{He}$ also expressed the belief that conservative political shifts have been occurring at the state and local levels of government. These too would be hard to detect econometrically and might, for recent years, be confused in econometric work with effects of reduced income growth or reduced federal support. 